\title{
Avaliação da cobertura do solo como indicador de gestão de recursos hídricos: um caso de estudo na sub-bacia do Córrego dos Bois, Minas Gerais
}

\author{
Evaluation of the land cover as water management indicator: \\ a case study at Córrego dos Bois sub-basin, Minas Gerais \\ Mirian de Sousa Silva', Inácio Thomaz Bueno², Fausto Weimar Acerbi Júnior³, \\ Luis Antônio Coimbra Borges ${ }^{4}$, Natalino Calegario ${ }^{4}$
}

口

\begin{abstract}
RESUMO
No presente artigo realizou-se uma avaliação da ocupação da sub-bacia Córrego dos Bois, no município de Oliveira (MG) - com base nos resultados foram obtidas as classes de uso e ocupação do solo, delimitadas as áreas de preservação permanente, identificadas a ocorrência de conflito entre o uso do solo e a legislação e elaborados indicadores ambientais. Foi construído um mosaico a partir de três imagens provenientes dos satélites RapidEye. O método de classificação adotado foi a classificação orientada a objetos e para isso utilizou-se o software Ecognition Developer 8.0\%. O algoritmo utilizado no processo de classificação foi o vizinho mais próximo, que leva em consideração a proximidade dos objetos segmentados na imagem em um espaço de características. A avaliação da exatidão da classificação foi realizada com base na coleta de amostras de acurácia obtidas aleatoriamente em áreas previamente conhecidas na imagem. Foram obtidas as classes água, café, eucalipto, floresta, infraestrutura, mineração, pastagem, rodovia, solo exposto e várzea, e encontradas somente duas categorias de áreas de preservação permanente (APP), ao longo dos cursos d'água e no entorno das nascentes. Conclui-se que a área total da sub-bacia Córrego dos Bois é de 1.540,18 ha, dos quais 40,70\% são ocupados por pastagem, 35,84\%, por cafezal e 18,84\%, por vegetação nativa. O conflito do uso e da ocupação do solo nas áreas destinadas à preservação corresponde a 25,58\% do território das APPS.
\end{abstract}

Palavras-chave: cobertura vegetal; imagens RapidEye; indicador ambiental.

\begin{abstract}
In the present work, we evaluated the occupation of the Córrego dos Bois sub-basin, in the municipality of Oliveira County, Minas Gerais State, in Brazil - based on it, it has been obtained land cover classes, defined areas of permanent preservation, identified the conflict among land use and environmental laws, and calculated environmental indicators. Initially, it was constructed a mosaic of three RapidEye images. The classification method used was the object-based classification with the Ecognition Developer 8.0 $0^{\circ}$ software. The classifier algorithm applied was the nearest neighbor, which takes in account the proximity of segmented objects in an image in the feature space. A random sampling, in some previously defined areas, performed the evaluation of the classification accuracy. The land cover classes obtained were water bodies, coffee farming, Eucalyptus forests, native forests, buildings, mining, pasture, road, bare land and floodplain. It was identified only two categories of preservation permanent areas in the study area: adjacent to rivers and springs. It concludes that the total area of the Córrego dos Bois sub-basin is 1,540.18 hectares, where $40.70 \%$ are pastures, $35.84 \%$ are coffee plantations, and $18.84 \%$ are native forests. The corresponding conflict of the land use in the preservation areas is $25.58 \%$.
\end{abstract}

Keywords: vegetal coverage; RapidEye images; environmental indicator.

\section{INTRODUÇÃO}

Um dos principais problemas ambientais enfrentados atualmente é a denominada "Crise Hídrica", que tem atingido principalmente o Sistema Cantareira na região de São Paulo e outros reservatórios na Região Sudeste do Brasil.
Os principais fatores que levaram à diminuição dos níveis dos reservatórios foram: o período chuvoso entre 2013 e 2014, que foi atipicamente seco, o aumento efetivo do consumo e desperdício de água pela população, a alteração do uso do solo nas áreas de preservação permanente (APP), a erosão e o assoreamento dos cursos d'água, a falta de planejamento

\section{$\square$}

'Doutoranda do Departamento de Ciências Florestais da Universidade Federal de Lavras (UFLA) - Lavras (MG), Brasil.

${ }^{2}$ Mestrando do Departamento de Ciências Florestais da UFLA - Lavras (MG), Brasil.

3Professor associado I do Departamento de Ciências Florestais da UFLA - Lavras (MG), Brasil.

4Professor adjunto do Departamento de Ciências Florestais da UFLA - Lavras (MG), Brasil.

Endereço para correspondência: Mirian de Sousa Silva - Universidade Federal de Lavras, Departamento de Ciências Florestais - Caixa Posta 3037 - $37200-000$ - Lavras (MG), Brasil - E-mail: mirianfloresta@gmail.com

Recebido: 22/06/15 - Aceito: 01/07/16 - Reg. ABES: 149673 
e a má gestão dos recursos hídricos (COELHO et al., 2016; TARGA \& BATISTA, 2015).

Nesse sentido, as áreas onde estão localizados os mananciais de abastecimento público devem ser alvo de atenção específica por parte dos pesquisadores, dos gestores públicos e da comunidade local, a fim de alcançar o desenvolvimento sustentável desse sistema (BRASIL, 2014).

Os indicadores servem como importante instrumento de diagnóstico de uma determinada realidade com o intuito de auxiliar os tomadores de decisão (PEREIRA \& ORTEGA, 2012). Indicador é um parâmetro (propriedade medida ou observada) ou valor derivado de parâmetros que fornece informação sobre um determinado fenômeno (OECD, 1993).

A escolha dos indicadores depende inicialmente das necessidades dos usuários potenciais. Parte-se de um objetivo a partir do qual se identifica a necessidade de informações de apoio a decisão, em que tais informações são os indicadores (MALHEIROS et al., 2013).

Monitorar o progresso rumo ao desenvolvimento sustentável requer a identificação de indicadores operacionais que proporcionem unidades gerenciáveis de informações das condições econômicas, ambientais e sociais (BÖHRINGER \& JOCHEM, 2007).

Bitar e Braga (2013) descrevem que os indicadores ambientais revelam a situação dos recursos ambientais do meio físico (solo, água e ar), meio biótico (fauna e flora) e meio antrópico (ambiente construído).

$\mathrm{Na}$ determinação de indicadores ambientais para a gestão dos recursos hídricos, as técnicas de sensoriamento remoto e geoprocessamento se tornam ferramentas úteis e indispensáveis no monitoramento da dinâmica de uso e ocupação do solo, na delimitação das APPs e na identificação de conflito de uso do solo em bacias hidrográficas. De acordo com Rodrigues et al. (2007), as técnicas de sensoriamento remoto e geoprocessamento propiciam maior frequência na atualização de dados e agilidade no processamento e são economicamente viáveis.

Cada elemento constituinte da cobertura terrestre pode ser discriminado através de atributos espectrais, texturais, de forma e contexto, permitindo, assim, por meio de técnicas de geoprocessamento, a extração direta das informações presentes na paisagem e o mapeamento da cobertura terrestre (REIS et al., 2012).

O presente trabalho teve como objetivos:

- obter as classes de uso e ocupação do solo na sub-bacia do Córrego dos Bois, no município de Oliveira (MG), mediante a combinação de tecnologias de sensoriamento remoto e sistemas de informações geográficas;

- delimitar as APPs de acordo com as determinações do Código Florestal Brasileiro (Lei $\mathrm{n}^{\circ}$ 12.651/12) e identificar a ocorrência de conflito entre o uso do solo e a legislação na sub-bacia hidrográfica do Córrego dos Bois no município de Oliveira (MG);

- elaborar indicadores ambientais a partir dos resultados obtidos do uso e da ocupação do solo e da análise das APPs na sub-bacia do Córrego dos Bois, município de Oliveira (MG).
A sub-bacia do Córrego dos Bois foi selecionada por ser considerada o principal manancial de abastecimento público do município de Oliveira (MG) há mais de quatro décadas e pelo fato de que atualmente vem enfrentando dificuldades no abastecimento público decorrentes da crise hídrica, além de estar inserida em uma região propensa a erosões do tipo voçorocas.

\section{METODOLOGIA}

\section{Localização e características da área de estudo}

A área de estudo é a sub-bacia do Córrego dos Bois, localizada no município de Oliveira, no Estado de Minas Gerais, afluente do Rio Jacaré e inserida na Unidade de Planejamento e Gestão de Recursos Hídricos Rio das Mortes GD2 (UPGRH-GD2) (Figura 1). O Rio Jacaré é um dos afluentes do Rio Grande.

Encontra-se completamente na área rural do município de Oliveira (MG), cujas coordenadas geográficas são $20^{\circ} 48^{\prime} 46^{\prime \prime S}, 44^{\circ} 47^{\prime} 32^{\prime \prime O}$, e em uma área aproximada de 1.540 ha (Figura 2). A sub-bacia é cortada pela Rodovia Fernão Dias (BR-381), que liga São Paulo a Belo Horizonte, entre o km 626 e o $\mathrm{km} 629$, sentido sul. É considerada o principal manancial de abastecimento público do município (SAAE, 2014).

A população estimada para o município de Oliveira é de 41.562 habitantes (IBGE, 2015).

O clima de Oliveira, segundo a classificação climática de Köeppen, é $\mathrm{Cwb}$ - mesotérmico com verões brandos e suaves e estiagem de inverno. A precipitação e a temperatura média anuais são de $1.500 \mathrm{~mm}$ e $19^{\circ} \mathrm{C}$, respectivamente (PREFEITURA MUNICIPAL DE OLIVEIRA, 2011).

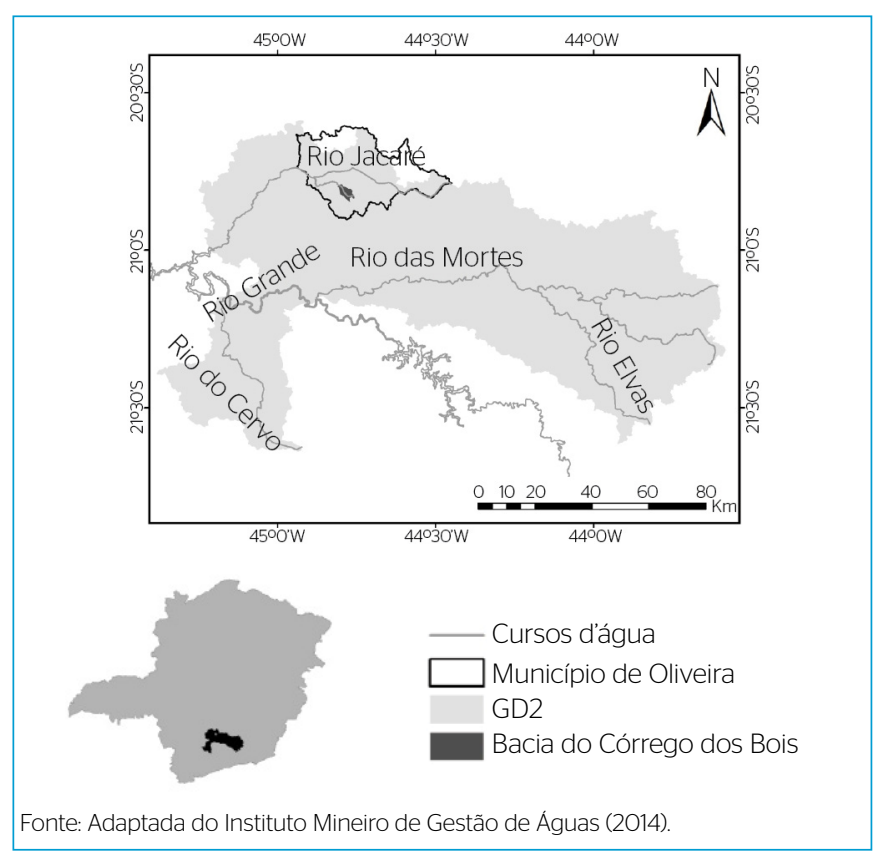

Figura 1 - Localização geográfica da área de estudo na UPGRH-GD2. 
A sub-bacia está inserida no bioma Mata Atlântica e, de acordo com o mapeamento da cobertura vegetal realizado em 2009, 11,88\% da sua área total está representada pela fitofisionomia de floresta estacional semidecidual montana (ZEE, 2014). A classificação do solo é do tipo Latossolo Vermelho-Amarelo (IBGE, 2001).

\section{Mapeamento das classes de cobertura e uso do solo}

Foi construído um mosaico a partir de três imagens provenientes dos satélites RapidEye, correspondendo as cenas 2329415, 2329515, 2329516, com as respectivas datas de 14 de março de 2010, 11 de março de 2010 e 12 de fevereiro de 2010. As imagens RapidEye possuem alta resolução espacial (5 metros) e boa resolução espectral (5 bandas), proporcionando um alto nível de detalhamento no mapeamento da área de estudo.

O método de classificação adotado foi a classificação orientada a objetos e para isso utilizou-se o software Ecognition Developer 8. $0^{\circledR}$ (TRIMBLE, 2010). O método de classificação orientada a objetos consiste em agrupar pixels de valores similares em regiões de acordo com um parâmetro de escala pré-estabelecido pelo usuário, segmentando a imagem em objetos homogêneos, que atendam a um determinado fim (BOTELHO \& CENTENO, 2005). O algoritmo utilizado no processo de segmentação foi o de multirresolução proposto por Baatz e Schäpe (2000), que leva em consideração critérios de cor, forma e escala para definir a homogeneidade dos segmentos. Após a segmentação, foram coletadas amostras de treinamento contendo objetos para as classes água, café, eucalipto, floresta, infraestrutura, mineração, pastagem,

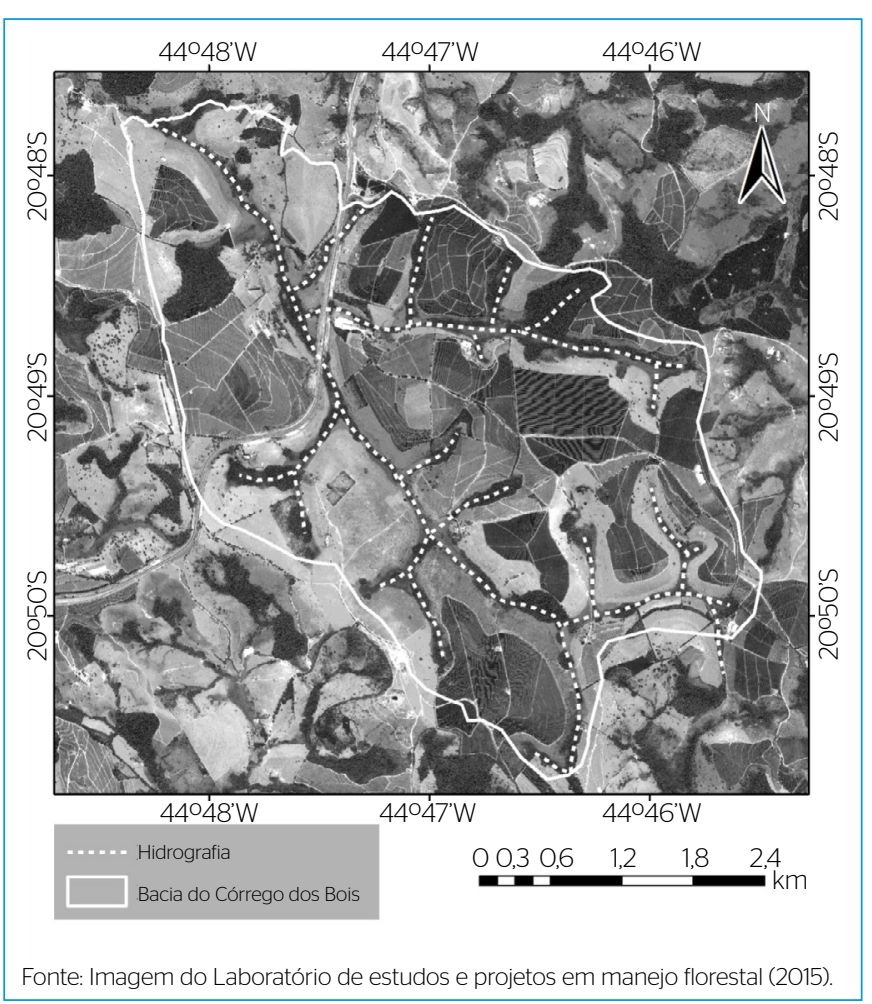

Figura 2 - Imagem da sub-bacia e da hidrografia do Córrego dos Bois, Oliveira (MG). rodovia, solo exposto e várzea, definidas na área de estudo. O algoritmo utilizado para a classificação foi o vizinho mais próximo.

A avaliação da exatidão da classificação foi realizada com base na coleta de amostras de acurácia obtidas aleatoriamente em áreas previamente conhecidas na imagem. Essa informação foi comparada com os resultados da classificação através de uma matriz de confusão, na qual informações de acurácia global, do produtor e do usuário, são extraídas para a certificação da qualidade do mapeamento, conforme metodologia descrita por Congalton e Green (2009).

\section{Delimitação das áreas de preservação permanente}

A delimitação das APPs ao longo dos cursos d'água (APP-1) seguiram as especificações presentes nos art. $4^{\circ}$ e $5^{\circ}$ da Lei no 12.651 , de 25 de maio de 2012, nas quais, para cursos d'água com largura inferior a 10 metros, a APP deve ser de 30 metros, e para nascentes (APP-2), a APP deve ter um raio mínimo de 50 metros. A delimitação das APPs foi feita por meio do software ArcGIS $10.1^{\circledR}$ (ESRI, 2011), a base vetorial utilizada foi a drenagem fornecida pelo Serviço Autônomo de Água e Esgoto do município de Oliveira e, por meio do comando buffer, delimitaram-se as APPs conforme especificado na legislação; logo após, mesclaram-se as duas categorias de APPs por meio do comando merge; depois, com o comando dissolve, retiraram-se as sobreposições de áreas de forma que as APPs se tornaram um único arquivo vetorial.

Para delimitar as APPs de topo de morros, montes, montanhas e serras com altura mínima de $100 \mathrm{~m}$ e inclinação média maior que $25^{\circ}$ e as APPs de encostas ou partes destas com declividade superior a $45^{\circ}$, equivalente a $100 \%$ na linha de maior declive, foi empregada a metodologia de Santos (2013), utilizando como base o Modelo de Elevação Digital.

\section{Análise de conflito nas áreas de preservação permanente}

Para avaliar a presença de vegetação nativa dentro das APPs, foi feita a interseção das camadas de cobertura do uso do solo e da camada das APPs.

\section{RESULTADOS E DISCUSSÃO}

\section{Classes de uso e ocupação do solo}

A classificação obteve uma acurácia global de 85,28\% e o valor do índice Kappa de 0,85. Segundo Congalton e Green (2009), valores de coeficiente Kappa entre 0,8 e 1,0 indicam que a classificação alcançou um resultado satisfatório.

Trata-se de uma sub-bacia hidrográfica com $76,54 \%$ de sua área total ocupada com atividade agropecuária, sendo que 40,70 e 35,84\% da área total é ocupada, respectivamente, por pastagem e café (Figura 3 e Tabela 1). 
Esses dados revelam que a cultura do café na região constitui uma atividade bem consolidada e que não permitiu grandes avanços no setor de silvicultura nos últimos anos (1,17\% de eucalipto).

A pastagem se destaca com a maior porcentagem do uso do solo formada para alimentação do rebanho bovino. Somada à cultura do café, a ocupação da sub-bacia teve como consequência um baixo percentual de vegetação

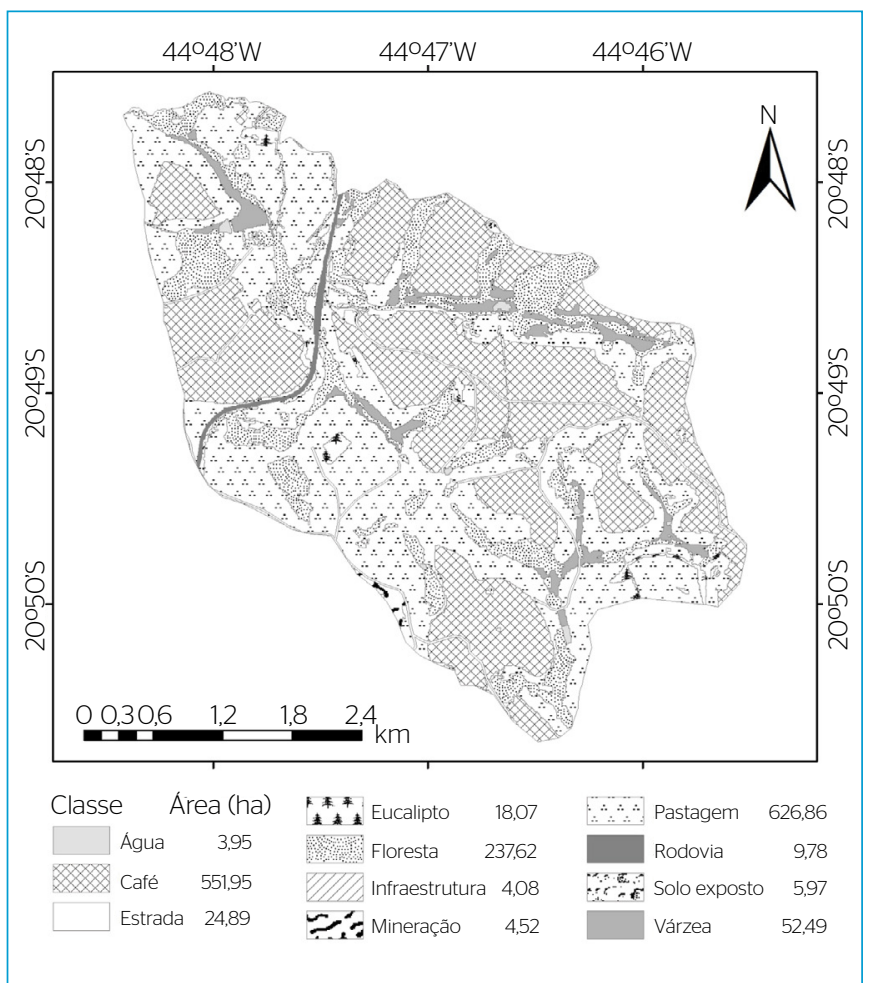

Figura 3 - Uso e ocupação do solo na sub-bacia do Córrego dos Bois, Oliveira (MG).

Tabela 1 - Uso e ocupação do solo na sub-bacia do Córrego dos Bois, Oliveira (MG), em área e porcentagem.

\begin{tabular}{|c|c|c|c|}
\hline Uso & Classes de ocupação & Hectares & $\%$ \\
\hline \multirow{2}{*}{$\begin{array}{l}\text { Agrícola/ } \\
\text { Pastagem }\end{array}$} & Pastagem & 626,86 & 40,70 \\
\hline & Café & 551,95 & 35,84 \\
\hline Reflorestamento & Eucalipto & 18,07 & 1,17 \\
\hline \multirow[t]{2}{*}{$\begin{array}{l}\text { Vegetação } \\
\text { nativa }\end{array}$} & $\begin{array}{c}\text { Floresta } \\
\text { (remanescentes } \\
\text { florestais) }\end{array}$ & 237,62 & 15,43 \\
\hline & Várzea & 52,49 & 3,41 \\
\hline Água & $\begin{array}{l}\text { Água (cursos d’água, } \\
\text { nascentes e represas) }\end{array}$ & 3,95 & 0,26 \\
\hline \multirow{2}{*}{$\begin{array}{l}\text { Acesso e } \\
\text { transporte }\end{array}$} & Estrada (rural) & 24,89 & 1,62 \\
\hline & Rodovia BR-381 & 9,78 & 0,63 \\
\hline \multirow{3}{*}{ Outros } & Solo exposto & 5,97 & 0,39 \\
\hline & Mineração & 4,52 & 0,29 \\
\hline & $\begin{array}{c}\text { Infraestrutura (casas e } \\
\text { benfeitorias) }\end{array}$ & 4,08 & 0,26 \\
\hline Total & & $1.540,18$ & 100,00 \\
\hline
\end{tabular}

nativa (18,84\%), não atendendo ao limite mínimo do Código Florestal de 2012, que exige 20\% de Reserva Legal (RL), admitindo o cômputo da APP.

Para computar as APPs no cálculo do percentual da RL (Lei $\mathrm{n}^{\circ} 12.651 / 2012$, Artigo 15, Inciso II), será admitido o cômputo das APPs no cálculo do percentual da RL desde que a área a ser computada esteja conservada ou em processo de recuperação, conforme a comprovação do proprietário ao órgão estadual integrante do Sistema Nacional do Meio Ambiente (SISNAMA). Dos 18,84\% de vegetação nativa na sub-bacia (Tabela 1), 11,84\% de vegetação nativa pode ser instituída como RL porque não é APP. Chama-se atenção que desses $18,84 \%$ de vegetação nativa apenas $7 \%$ (5,91\% de florestas e 1,09\% de várzea) é APP (Tabela 2). Vale ressaltar que, no artigo 67 do Novo Código Florestal, "os imóveis rurais que detinham, em 22 de julho de 2008, área de até 4 (quatro) módulos fiscais e que possuam remanescente de vegetação nativa em percentuais inferiores ao previsto no artigo 12, a Reserva Legal será constituída com a área ocupada com a vegetação nativa existente em 22 de julho de 2008, vedadas novas conversões para uso alternativo do solo", ou seja, atendendo a esse dispositivo, não precisam recompor a RL. Dessa forma, pode-se computar esses 7\% juntamente com os $11,84 \%$ restantes de vegetação nativa no cálculo da RL. Ainda assim, a RL não alcançará o mínimo de $20 \%$ exigido para Minas Gerais.

Os remanescentes florestais ocupam $15,43 \%$ da área total. Essa porcentagem é próxima da encontrada no Mapeamento da Cobertura Vegetal de 2009, que corresponde a $11,88 \%$ da sua área representada pela fitofisionomia de floresta estacional semidecidual montana (ZEE, 2014). A diferença de vegetação natural encontrada na sub-bacia Córrego dos Bois se deve à melhor resolução espacial do sensor RapidEye (5 m) utilizado neste estudo, enquanto o ZEE utilizou o sensor Landsat ${ }^{\mathrm{TM}}$ $(30 \mathrm{~m})$, conferindo assim maior exatidão nos resultados desta pesquisa.

\section{Áreas de preservação permanente}

Segundo o Novo Código Florestal Brasileiro, estabelecido pela Lei ${ }^{\circ} 12.651$, de 25 de maio de 2012, artigo 3º inciso II, entende-se por APP “área protegida, coberta ou não por vegetação nativa, com a função ambiental de preservar os recursos hídricos, a paisagem, a estabilidade geológica e a biodiversidade, além de facilitar o fluxo gênico de fauna e flora, proteger o solo e assegurar o bem-estar das populações humanas" (BRASIL, 2012).

A seguir é apresentada (Tabela 3) a área ocupada por cada categoria de APP na sub-bacia Córrego dos Bois no município de Oliveira (MG), de acordo com as metragens estabelecidas no Artigo $4^{\circ}$ da Lei ${ }^{\circ}$ 12.651/12.

As APPs ao longo dos cursos d'água (APP-1) ocupam as áreas mais sensíveis de uma bacia hidrográfica e garantem a estabilização das margens dos rios, sendo consideradas importantes no controle da qualidade da água por reduzirem a ocorrência de escoamento superficial, que pode causar erosão e arraste de nutrientes, produtos químicos e sedimentos para os cursos d'água (EUGENIO et al., 2011). A área ocupada por essas APPs é de 126,77 ha, o que representa 8,23\% da área total da sub-bacia. 
As áreas ao entorno das nascentes, correspondentes a APP-2, representam $1,17 \%$ da área da sub-bacia e totalizam 17,99 ha. Essas áreas são fundamentais para a manutenção da qualidade e quantidade de água das nascentes, influenciando diretamente no armazenamento da água subterrânea e no regime dos cursos d'água (PINTO et al., 2004).

Ressalta-se que não foram encontradas APPs relacionadas às categorias topo de morros, montes, montanhas e serras com altura mínima de $100 \mathrm{~m}$ e inclinação média maior que $25^{\circ}$ e encostas ou partes destas com declividade superior a $45^{\circ}$, equivalente a $100 \%$ na linha de maior declive.

Observa-se ainda que as APPs ocupam uma área total de 144,76 ha, de um total de 1.540 ha da área da sub-bacia, representando 9,4\% de áreas legalmente protegidas.

\section{Uso e ocupação do solo em áreas de preservação permanente}

A Figura 4 e a Tabela 2 representam o uso e a ocupação do solo nas áreas destinadas à preservação na sub-bacia do Córrego dos Bois.

Verifica-se que a maior parte das APPs é ocupada por floresta estacional semidecidual montana e pastagem, correspondendo a 62,96 e $22,52 \%$, respectivamente. As áreas de várzea ocupam 11,46\% das áreas destinadas à preservação. $\mathrm{O}$ café, a rodovia, o eucalipto e a estrada ocupam, respectivamente, $1,47,0,81,0,60$ e $0,18 \%$ das APPs.

Tabela 2 - Quantificação do uso e da cobertura do solo nas áreas de preservação permanente da sub-bacia Córrego dos Bois, Oliveira (MG).

\begin{tabular}{l|c|c}
\multirow{2}{*}{ Classe de uso do solo } & \multicolumn{2}{|c}{ APP } \\
\cline { 2 - 3 } Floresta & Área (ha) & $\%$ \\
\hline Pastagem & 91,13 & 62,96 \\
\hline Várzea & 32,61 & 22,52 \\
\hline Café & 16,60 & 11,46 \\
\hline Rodovia & 2,12 & 1,47 \\
\hline Eucalipto & 1,17 & 0,81 \\
\hline Estrada & 0,87 & 0,60 \\
\hline Infraestrutura & 0,26 & 0,18 \\
\hline Solo exposto & 0,00 & 0,00 \\
\hline Total & 0,00 & 0,00 \\
\hline
\end{tabular}

APP: área de preservação permanente

Tabela 3 - Porcentagem de áreas ocupadas pelas áreas de preservação permanente na sub-bacia do Córrego dos Bois, Oliveira (MG).

\begin{tabular}{l|c|c|c} 
APPs & Caracteristica & Área (ha) & $\begin{array}{c}\text { \% (área ocupada na } \\
\text { sub-bacia) }\end{array}$ \\
\hline APP-1 & $30 \mathrm{~m}$ & 126,77 & 8,23 \\
\hline APP-2 & Raio de $50 \mathrm{~m}$ & 17,99 & 1,17 \\
\hline Total & Sem sobreposições & 144,76 & 9,40
\end{tabular}

APP-1: área de preservação permanente ao longo dos cursos d’água; APP-2: área de preservação permanente no entorno das nascentes.
O conflito do uso e da ocupação do solo nas áreas destinadas à preservação corresponde a 25,58\% do território das APPs, evidenciando a presença de atividade antrópica nas áreas legalmente protegidas pela legislação ambiental. Segundo Silva et al. (2010), a preservação das APPs pode ser considerada um indicador de sustentabilidade na sub-bacia devido à função ambiental que essas áreas desempenham nos ambientes com os quais estão envolvidas.

Os resultados do uso e da ocupação do solo em cada categoria de APPs estão dispostos na Tabela 4. Observa-se que as áreas de preservação correspondentes aos cursos d'água (APP-1) possuem $75,30 \%$ das suas áreas cobertas por vegetação nativa (classes de floresta e várzea).

As áreas de pastagem ocupam 22,50\% das APPs dos cursos d'água e 22,62\% das APPs das nascentes, representando o uso mais conflitante das APPs nas duas categorias.

Em um trabalho realizado na bacia hidrográfica do rio Alegre, no município de Alegre (ES), as classes cafezal e pastagem foram as de maior ocorrência das categorias de APPs mapeadas, ocupando respectivamente 10,24 e 64,49\% (NASCIMENTO et al., 2005).

De acordo com esses resultados, deve-se ressaltar que as áreas de pastagem são ocupadas por rebanhos e, caso essas áreas de APPs ocupadas por pastagem não forem cercadas, estes poderão invadir as APPs dos cursos d'água e das nascentes, comendo as mudas e, assim, interferindo negativamente no processo de regeneração natural, além de compactarem o solo com o pisoteamento, dificultando, dessa maneira,

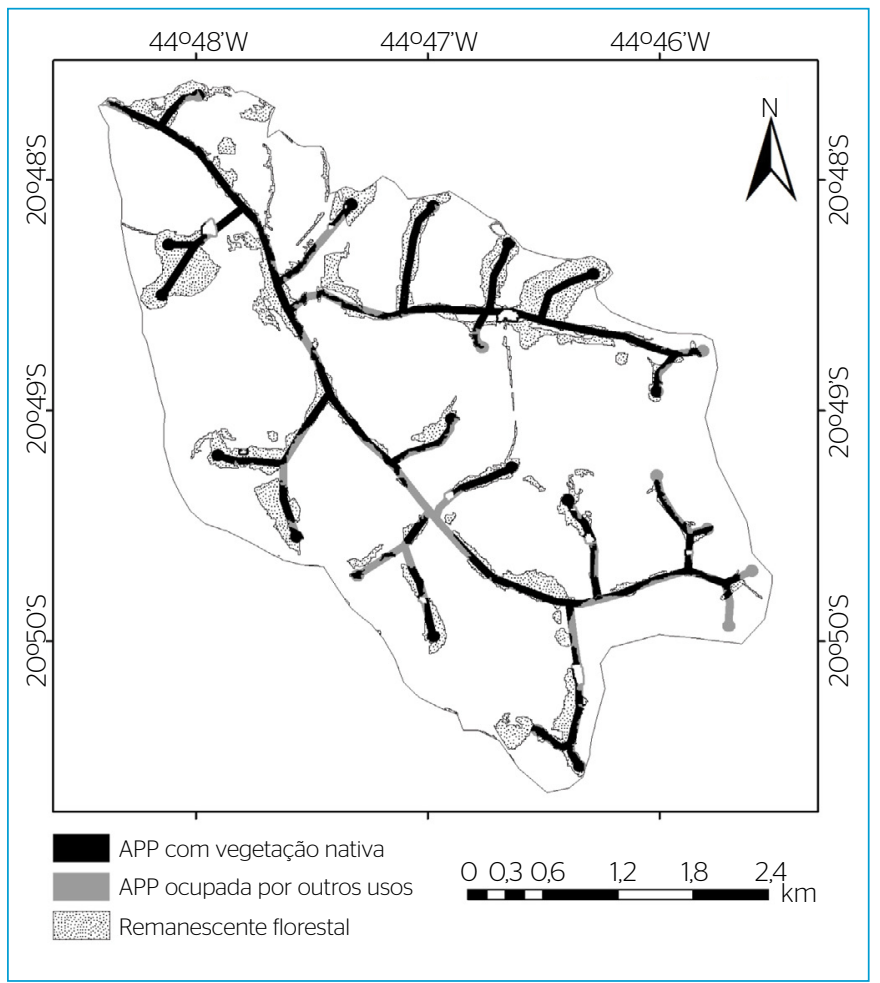

Figura 4 - Áreas de preservação permanente na sub-bacia do Córrego dos Bois, Oliveira (MG). 
a infiltração d'água no solo. A recuperação das APPs deve seguir a regra contida no artigo 61-A do Código Florestal detalhada na Tabela 5, que varia de acordo com o tamanho do imóvel rural (módulos fiscais).

A manutenção das áreas vegetadas no entorno dos cursos d'água garante a proteção dos recursos hídricos, a integridade ecológica nas áreas de várzea e o fluxo gênico entre remanescentes florestais e fornece alimentação e abrigo para a fauna, atuando como barreiras naturais contra a disseminação de pragas e doenças nas lavouras (BELLUTA et al., 2011).

\section{Elaboração dos indicadores ambientais}

A análise do uso e da ocupação do solo e das APPs permitiu a elaboração de quatro indicadores ambientais (Tabela 6).

O maior valor do indicador área com uso agropecuário e o menor valor do indicador área com vegetação nativa apontam um pior desempenho para o alcance do desenvolvimento local integrado e sustentável (KRONEMBERGER; CARVALHO; CÉSAR JUNIOR, 2004). Estes mesmos autores, em um trabalho realizado na bacia do Jurumirim, em Angra dos Reis (RJ), encontraram 70\% da área da bacia ocupada com floresta nativa e $26 \%$ ocupada com uso agropecuário.

Já na bacia hidrográfica do rio Atibaia, relacionada a dois importantes centros urbanos e econômicos do Brasil, as regiões metropolitanas de Campinas e de São Paulo, cerca de 70\% da bacia está sob a intervenção

Tabela 4 - Quantificação do uso e da cobertura do solo em cada categoria de áreas de preservação permanente da sub-bacia Córrego dos Bois, Oliveira (MG).

\begin{tabular}{l|c|c|c|c}
\multirow{2}{*}{$\begin{array}{l}\text { Classes de uso } \\
\text { do solo }\end{array}$} & \multicolumn{2}{|c|}{ APP-1 } & \multicolumn{2}{c}{ APP-2 } \\
\cline { 2 - 5 } Floresta & Área (ha) & $\%$ & Área (ha) & $\%$ \\
\hline Pastagem & 79,00 & 62,31 & 12,14 & 67,49 \\
\hline Várzea & 28,53 & 22,50 & 4,07 & 22,62 \\
\hline Café & 16,47 & 12,99 & 0,13 & 0,72 \\
\hline Rodovia & 0,87 & 0,69 & 1,25 & 6,95 \\
\hline Eucalipto & 0,17 & 0,93 & 0,00 & 0,00 \\
\hline Estrada & 0,26 & 0,37 & 0,40 & 2,22 \\
\hline Infraestrutura & 0,00 & 0,00 & 0,00 & 0,00 \\
\hline Solo exposto & 0,00 & 0,00 & 0,00 & 0,00 \\
\hline Total & 126,77 & 100,00 & 17,99 & 100,00 \\
\hline
\end{tabular}

APP-1: ao longo dos cursos d’água; APP-2: entorno das nascentes.

Tabela 5 - Recomposição mínima das áreas de preservação permanente de acordo com o tamanho do imóvel rural em módulos fiscais.

\begin{tabular}{l|c|c}
$\begin{array}{l}\text { Área do imóvel rural } \\
\text { (módulo fiscal) }\end{array}$ & $\begin{array}{c}\text { Faixas marginais } \\
\text { do curso d'água }(\mathrm{m})\end{array}$ & $\begin{array}{c}\text { Entorno de } \\
\text { nascentes }(\mathrm{m})\end{array}$ \\
\hline$\leq 1$ & 5 & 15 \\
\hline$>1$ a 2 & 8 & 15 \\
\hline$>2$ a 4 & 15 & 15 \\
\hline$>4$ & $*$ & 15 \\
\hline
\end{tabular}

*De acordo com o plano de recuperação ambiental, observando o mínimo de $20 \mathrm{~m}$ e o máximo de 100 m. Fonte: Adaptado de Laudares (2014)
Tabela 6 - Indicadores ambientais elaborados a partir da análise de uso e ocupação do solo e das áreas de preservação permanente na sub-bacia do Córrego dos Bois, Oliveira (MG).

\begin{tabular}{|c|c|c|c|}
\hline Dimensão & Tema & Indicador & $\begin{array}{c}\text { Valor do } \\
\text { indicador (\%) }\end{array}$ \\
\hline \multirow{4}{*}{ Ambiental } & \multirow[t]{2}{*}{ Uso do solo } & $\begin{array}{l}\text { Área com uso } \\
\text { agropecuário } \\
\text { (\% da área da } \\
\text { sub-bacia) }\end{array}$ & 76,54 \\
\hline & & $\begin{array}{c}\text { Área com vegetação } \\
\text { nativa (\% da área da } \\
\text { sub-bacia) }\end{array}$ & 18,84 \\
\hline & \multirow[t]{2}{*}{$\begin{array}{l}\text { Legislação } \\
\text { (Lei 12.651/12) }\end{array}$} & $\begin{array}{c}\text { APPs dos cursos } \\
\text { d'água } \\
\text { (\% das APPs dos } \\
\text { cursos d'água } \\
\text { protegidas com } \\
\text { vegetação nativa) }\end{array}$ & 75,31 \\
\hline & & $\begin{array}{l}\text { APPs das nascentes } \\
\text { (\% das APPs das } \\
\text { nascentes protegidas } \\
\text { com vegetação nativa) }\end{array}$ & 68,20 \\
\hline
\end{tabular}

de alguma atividade antrópica, seja de uso rural, urbano, silvicultura, pastagem ou solo exposto (DEMANBORO et al., 2013).

\section{CONCLUSÕES}

A partir da metodologia aplicada, utilizando as técnicas de processamento e análise das imagens RapidEye, conclui-se que o geoprocessamento constitui poderosa ferramenta na construção de indicadores ambientais para avaliação da ocupação de sub-bacia.

A área total da sub-bacia Córrego dos Bois é de 1.540,18 ha, dos quais $40,70 \%$ são ocupados por pastagem, $35,84 \%$, por cafezal e $18,84 \%$, por vegetação nativa.

O conflito do uso e da ocupação do solo nas áreas destinadas a preservação corresponde a 25,58\% do território das APPs, o que evidencia a presença de atividade antrópica nas áreas legalmente protegidas pela legislação ambiental. O uso conflitivo mais comum nas APPs é a pastagem.

A pastagem se destaca com a maior porcentagem do uso do solo formada para alimentação do rebanho bovino. Somada à cultura do café, a ocupação da sub-bacia teve como consequência um baixo percentual de vegetação nativa $(18,84 \%)$, não atendendo ao limite mínimo do Código Florestal de 2012, que exige 20\% de RL, admitindo o cômputo da APP.

As APPs localizadas ao longo dos cursos d'água e no entorno das nascentes apresentaram áreas protegidas cobertas com vegetação nativa, possuindo respectivamente $75,30 \%$ e $68,21 \%$ do seu território cobertos por floresta semidecídua e várzea.

É necessária a adoção de medidas de recuperação das APPs, aproximadamente $36 \mathrm{ha}$, uma vez que desmatamentos e outros usos incorretos dos solos podem incidir na quantidade e qualidade 
da água do manancial. No entanto, com a flexibilização do Novo Código Florestal, cada imóvel pode ter uma variação da faixa de APPs a ser recomposta que varia de acordo com o tamanho do imóvel rural (módulos fiscais).

Em um estudo mais aprofundado sobre a ocupação do solo no local e sua sustentabilidade, é aconselhável examinar o histórico de ocupação do café na região, o seu manejo e as suas perspectivas futuras.
Além disso, sugere-se o desenvolvimento de pesquisas que permitam avaliar o manejo da pastagem e as questões sociais e econômicas da sub-bacia.

Recomenda-se ao poder público de Oliveira (MG) o desenvolvimento de ações de proteção florestal e restauração de áreas degradadas que margeiam os cursos d'água, como o Projeto Conservador das Águas, desenvolvido na sub-bacia das Posses, em Extrema (MG), que tem como objetivo a implantação do conceito de serviços ambientais.

\section{REFERÊNCIAS}

BAATZ, M. \& SCHÄPE, A. (2000) Multiresolution segmentation: an optimization approach for high quality multiscale image segmentation. In: Strobl, J., Blaschke T., Griesebner, G. (eds.): Angewandte Geographische Informationsverarbeitung XII. Wichmann: Heidelberg. p. 12-23.

BELLUTA, I.; NEVES, R. C. F.; ZAMPIERI, F. E. S.; SILVA, R. F. B.; SARTORI, A. A. C.; ZIMBACK, C. R. L. (2011) Aplicação de técnica de geoprocessamento em áreas degradadas de mata ciliar e sua correlação com qualidade da água numa sub-bacia hidrográfica. Irriga, Botucatu, v. 16, n. 2, p. 177-198, abr.jun.

BITAR, O. Y. \& BRAGA, T. O. (2013) Indicadores ambientais aplicados à gestão municipal. In: Indicadores de Sustentabilidade e Gestão Ambiental. Barueri (SP): Manole. 743p.

BÖHRINGER, C. \& JOCHEM, P. E. P. (2007) Measuring the immeasurable - A survey of sustainability indices. Ecological Economics, v. 63, n. 1, p. 1-8.

BOTELHO, M. F. \& CENTENO, J. A. S. (2005) Uso integrado de imagem de alta resolução espacial e altura derivada do laser scanner na escolha do classificador orientado a região. Boletim de Ciências Geodésicas, Curitiba, v. 11, n. 1, p. 71-87, jan./jun.

BRASIL. Lei n. 12.651, de 25 de maio de 2012. Dispõe sobre a proteção da vegetação nativa. Disponível em: <www.planalto. gov.br/ccivil_03/_ato2011-2014/2012/lei//12651.htm>. Acesso em: 10 dez. 2014.

BRASIL. Ministério do Meio Ambiente. Mananciais. Brasília, 2014. Disponível em: <www.mma.gov.br/cidades-sustentaveis/ aguas-urbanas/mananciais>. Acesso em: 30 jan. 2014.

COELHO, C. A. S.; OLIVEIRA, C. P.; AMBRIZZI, T.; REBOITA, M. S.; CARPENEDO, C. B.; CAMPOS, J. L. P. S.; TOMAZIELLO, A. C. N.; PAMPUCH, L. A.; CUSTODIO, M. S.; DUTRA, L. M M.; ROCHA, R. P.; REHBEIN, A. (2016) The 2014 southeast Brazil austral summer drought: regional scale 63 mechanisms and teleconnections. Climate Dynamics, Berlin, v. 46, n. 11, p. 3737-3752.

CONGALTON, R. G. \& GREEN, K. (2009) Assessing the Accuracy of Remotely Sensed Data: Principles and Practices. $2^{\circ}$ Ed. Boca Raton: CRC/Taylor \& Francis. 183p.

DEMANBORO, A. C.; LAURENTIS, G. L.; BETTINE, S. C. (2013) Cenários ambientais na bacia do rio Atibaia. Engenharia Sanitária e Ambiental, v. 18, n. 1, p. 27-37, jan./mar.
ESRI. (2011) ArcGIS Desktop 10. Environmental Systems Research Institute, Redlands.

EUGENIO, F. C.; SANTOS, A. R.; LOUZADA, F. L. R. de O.; PIMENTEL, L. B.; MOULIN, J. V. (2011) Identificação das áreas de preservação permanente no município de Alegre utilizando geotecnologia. Cerne, Lavras, v. 17, n. 4, p. 563-571, out./dez.

INSTITUTO BRASILEIRO DE GEOGRAFIA E ESTATÍSTICA - IBGE. Mapa de Solos do Brasil, 2001. Disponível em: <ftp://geoftp.ibge.gov.br/ mapas_tematicos/mapas_murais/solos.pdf>. Acesso em: 10 dez. 2014.

INSTITUTO BRASILEIRO DE GEOGRAFIA E ESTATISTICA. População estimada 2015. Disponível em: <www.cidades.ibge.gov. br>. Acesso em: 11 mai. 2015.

KRONEMBERGER, D. M. P.; CARVALHO, C. N.; CÉSAR JUNIOR, J. (2004) Indicadores de sustentabilidade em pequenas bacias hidrográficas: Uma aplicação do "Barômetro da Sustentabilidade" à bacia do Jurumirim (Angra dos Reis/RJ). Geochimica Brasilienses, v. 18, n. 2, p. 086-098.

LAUDARES, S. S. A. (2014) Atividades de baixo impacto e uso antrópico consolidado previstos no novo código florestal brasileiro (Lei no 12.651/12). 171p. Dissertação (Mestrado em Engenharia Florestal) - Universidade Federal de Lavras, Lavras.

MALHEIROS, T. F.; COUTINHO, S. M. V.; PHILIPPI JR, A. A. P. (2O13) Indicadores de sustentabilidade: uma abordagem conceitual. In: Indicadores de Sustentabilidade e Gestão Ambiental. Barueri (SP): Manole. 743 p.

NASCIMENTO, M. C.; SOARES, V. P.; RIBEIRO, C. A. A. S.; SILVA, E. (2005) Delimitação automática de áreas de preservação permanente (APP) e identificação de conflito de uso da terra na bacia hidrográfica do rio Alegre. In: Simpósio Brasileiro de Sensoriamento Remoto, Goiânia, Brasil, 16-21 abril, INPE, p. 2289-2296.

ORGANIZATION FOR ECONOMIC CO-OPERATION AND DEVELOPMENT - OECD. (1993) Environment Monographs nº 83 - OECD core set of indicators for environmental performance reviews. Paris. 39p.

PEREIRA, L. \& ORTEGA, E. (2012) A modified footprint method: The case study of Brazil. Ecological Indicators, v. 16, n. x. p. 113-127.

PINTO, L. V. A.; BOTELHO, S. A.; DAVIDE, A. C.; FERREIRA, E. (2004) Estudo das nascentes da bacia hidrográfica do Ribeirão Santa Cruz, Lavras, MG. Scientia Forestalis, Piracicaba, n. 65, p. 197-206, jun. 
PREFEITURA MUNICIPAL DE OLIVEIRA (PMO). (2011) Atlas Escolar Histórico, Geográfico e Cultural do Município de Oliveira Estado de Minas Gerais. Secretaria Municipal de Educação.

REIS, A. A.; TEIXIERA, M. D.; JÚNIOR, F. W. A.; MELLO, J. M.; LEITE, L. R.; SILVA, S. T. (2012) Análise do uso e ocupação da terra em áreas de preservação permanente no município de Lavras, MG. Ciência e agrotecnologia, Lavras, v. 36, n. 3, p. 300-308, maio/jun.

RODRIGUES, T. R. I.; ROCHA, A. M.; FILHO, A. P. (2007) Mapeamento de uso e ocupação das terras na Bacia do Baixo Curso do Rio São José do Dourados - SP por sistemas de informações geográficas e imagem de satélite. In: Anais do XII Simpósio brasileiro de sensoriamento remoto, 21-26 de abril, Florianópolis, Brasil: INPE, p. 6091-6097. Disponível em: <marte.sid.inpe.br/col/dpi.inpe.br/sbsr@80/2006/11.15.21.45.01/ doc/6091-6097.pdf>. Acesso em 10 dez. 2014.

SANTOS, A. P. S. (2013) Delimitação de Área de Preservação Permanente (APP) de Topo de Morros. In: Capítulo 17 do Material de Cartografia Digital /l do Curso de Engenharia de Agrimensura e Cartográfica da Universidade Federal de Viçosa. Viçosa.

SERVIÇO AUTÔNOMO DE ÁGUA E ESGOTO (SAAE). Dados operacionais. Disponível em: <www.saaeoliveira.com.br>. Acesso em: 10 dez. 2014.

SILVA, S. H. L.; BRAGA, F. A.; FONSECA, A. R. (2010) Análise de conflito entre legislação e uso da terra no município de Itabira MG. Caminhos de Geografia, Uberlândia, v. 11, n. 34, p. 131-144.

TARGA, M. S. \& BATISTA. G. T. (2015) Benefits and legacy of the water crisis in Brazil. Ambiente \& Água, Taubaté, v. 10, n. 2, p. 234-239.

TRIMBLE. eCognition` Developer 8.64 .0 reference book. 2010. Disponível em: <http://www.definiens.com/>. Acesso em: 11 mai. 2015.

ZONEAMENTO ECOLÓGICO ECONÔMICO DO ESTADO DE MINAS GERAIS (ZEE). Disponível em< www.zee.mg.gov.br>. Acesso em: 10 dez. 2014. 